\title{
Pattern of Poisoning Cases in a Tertiary Care Centre in South India - An Observational study
}

\author{
James Rajesh J' , Sampath Kumar $\mathbf{P}^{\mathbf{2}}$, Priyadarshee Pradhan ${ }^{3}$, Jothi Marie Feula $\mathrm{A}^{\mathbf{4}}$, Siva Reddy $\mathrm{B}^{\mathbf{5}}$ \\ ${ }^{1}$ Assistant Professor, Department of Forensic Medicine, Sri Venkateshwaraa Medical College Hospital \\ and Research Centre, Puducherry, ${ }^{2}$ Professor and Head, ${ }^{3}$ Professor, Department of Forensic Medicine, Sri \\ Ramachandra Medical College and Research Institute, Chennai, ${ }^{4}$ Senior Resident, Department of Physiology, \\ Jawaharlal Institute of Postgraduate Medical Education \& Research, Puducherry, ${ }^{5}$ Professor and Head, \\ Department of Forensic Medicine, Sri Venkateshwaraa Medical College Hospital and Research Centre, \\ Puducherry
}

\begin{abstract}
Poison is any substance which when administered, inhaled or ingested is capable of causing deleterious effects on the human body. This prospective study was carried out involving 353 cases of poisoning admitted in Sri Ramachandra Medical College \& Research Institute Porur, Chennai, during the period of June 2014June 2015. The demographic details were acquired from the patient, relatives, friends or the investigating officer and by going through the medical records and the inquest report. In the current study the maximum cases were in the age group of 20-29 years and the incidence decreased as the age increases and it was evident that the incidence of poisoning is more in case of females when compared to males. The material of maximum abuse was T.Alprazolam (10.8\%), followed by Rat Killer poison $(9.6 \%)$, and followed by Snake Strike (8.8\%), Organo Phosphorus Poisoning (8.5\%), and Multiple Tablet Overdose (8.2\%). 78\% consumed poison intentionally and are suicidal in nature, as no cases of homicidal poisoning were reported in the study group, rest of the $22 \%$ of cases, were of accidental in nature. Mortality wise analysis showed that dead cases count 13 in number which accounts to $3.5 \%$ of all poisoning cases.
\end{abstract}

Key Words: Pattern of poison, economic poisons, poisoning causes, outcome of poisoning

\section{Introduction}

Poison is any substance which when administered, inhaled or ingested is capable of causing deleterious effects on the human body. ${ }^{1}$ The substances that are used to control insects, weeds, fungi, bacteria, rodents, predatory animals, or other pests are termed as economic poisons $^{2}$

According to the World Health Organization (WHO) data released in the year 2012, the poisoning deaths were

\section{Corresponding author:}

\section{Dr. James Rajesh J}

Assistant Professor, Department of Forensic Medicine, Sri Venkateshwaraa Medical College Hospital and

Research Centre, Ariyur, Puducherry.

Email-james_rajesh143@yahoo.com

Mobile - 9443790021 estimated to be 193,460 worldwide. Of these deaths, $84 \%$ were reported in low and middle income countries. In the same year, poisoning was also reported to cause a huge loss of around 10.7 million disability adjusted life years (DALY). ${ }^{3}$ It is also estimated that deliberate ingestion of pesticides contribute to 370,000 deaths each year. 3 The incidence of poisoning in India is among the highest in the world, which is estimated that more than 50,000 people die every year from toxic exposure. ${ }^{4}$

In India organophosphorous compounds form the largest bulk of pesticide poisoning. ${ }^{4}$ The trend of poisoning has shown a change due to introduction of newer pesticides under different classes. Poisoning is a medico - legal, epidemiological, social problem, which is alarming and a constant threat to the society. To encounter this problem in a given area, knowledge about the poisons, their clinical aspects will not be sufficient. Various aspects of pattern of poisoning in that particular 
area is necessary, so that the law enforcing agencies, government and health departments can successfully bring down the poisoning incidence. With this broad view in mind, this study was carried out involving the data pertaining to all cases of poisoning admitted in Sri Ramachandra Medical College \& Research Institute between the period of June 2014 to June 2015.

\section{Materials and Method}

\section{Source of Data}

This prospective study was carried out involving 353 cases of poisoning admitted in Sri Ramachandra Medical College \& Research Institute, Sri Ramachandra University, Porur, Chennai, during the period of June 2014 to June 2015 . The study was approved by scientific and ethics committee of the institute.

\section{Inclusion Criteria}

- All cases of poisoning either suicidal or accidental, both directly admitted and referral cases during the period of June 2014 - June 2015.

- Snake Strike and Scorpion stings.

- Domestic as well as Commercial Poisoning.

\section{Exclusion Criteria}

- Cases without proper diagnosis (undetermined).

- Outside cases brought to SRMC mortuary with history of poisoning.

\section{Methodology}

The demographic details were acquired from the patient, relatives, friends or the investigating officer and by going through the medical records and the inquest report. Among the admitted cases, if some turn out to be fatal, post mortem examination was done and in that the stomach was examined for any peculiar odour and the mucosa was also examined. The routine viscera which includes the entire stomach and a small part of intestine with its contents, part of liver, half of each kidney, blood (10-30 ml), urine (30-50 ml) if possible were sent to forensic science laboratory for further evaluation.
Preservatives used were super saturated solution of sodium chloride for viscera and $10 \mathrm{mg} / \mathrm{ml}$ Sodium fluoride for blood and urine. All the data collected were complied and analyzed statistically using SPSS software version 15 .

\section{Observaton \& Results}

Distribution of study population based on age and gender is mentioned in table 1 . The minimum age affected was 1 year old and maximum age affected was 80 years. Mean age of the study population was 28 years. Incidence of poisoning was also reported to be more in case of females when compared to males. Distribution of poisoning based on time of day (Annexure 1) and manner of poisoning is mentioned in Table 2, which shows that the frequency of poisoning is more in the evening and suicidal poisoning is more common. Among the type of poisoning Tab. Alprazolam is the most common agent used. Out of total 353 cases, death was reported in 13 cases $(3.7 \%)$ as shown in table 4 .

Table 1: Distribution of Study population based on age and gender $(n=353)$

\begin{tabular}{|l|l|}
\hline Age ( years ) & Frequency (\%) \\
\hline $1-9$ & $39(11.0)$ \\
\hline $10-19$ & $57(16.1)$ \\
\hline $20-29$ & $127(36.0)$ \\
\hline $30-39$ & $55(15.6)$ \\
\hline $40-49$ & $34(9.6)$ \\
\hline $50-59$ & $27(7.6)$ \\
\hline $60-69$ & $9(2.5)$ \\
\hline $70-79$ & $4(1.1)$ \\
\hline $80-89$ & $1(0.3)$ \\
\hline Gender & Frequency (\%) \\
\hline Male & $160(45.3)$ \\
\hline Female & $193(54.7)$ \\
\hline
\end{tabular}


Table 2 : Distribution of Study population based on the time and Manner of poisoning $(n=353)$

\begin{tabular}{|l|l|}
\hline Time & Frequency (\%) \\
\hline Morning & $96(27.2)$ \\
\hline Afternoon & $96(27.2)$ \\
\hline Evening & $110(31.2)$ \\
\hline Night & $51(14.4)$ \\
\hline & \\
\hline Manner & Frequency (\%) \\
\hline Suicidal & $275(77.9)$ \\
\hline Accidental & $78(22.1)$ \\
\hline
\end{tabular}

Table 3: Final outcome of poisoning cases $(n=353)$

\begin{tabular}{|l|l|}
\hline Final Outcome & Frequency $\mathbf{( \% )}$ \\
\hline Alive & $237(67.1)$ \\
\hline Dead & $13(3.7)$ \\
\hline Refereed to other hospitals & $103(29.2)$ \\
\hline
\end{tabular}

\section{Discussion}

The total number of cases admitted in Sri Ramachandra Medical College and Research Institute from June 2014 to June 2015 was 26,190 cases, out of which 4,498 cases were Medico-Legal Cases (MLC). Among the MLC, poisoning accounts for 353 cases. As the institute is a tertiary care centre, the numbers of cases are more when compared to most of the other studies to which this research work is compared.

In the current study age-wise distribution of poisoning cases revealed that the maximum cases are in the age group of 20-29 years and the incidence decreased as the age increases (Table 1). The minimum age affected was 1 year old and maximum age affected was 80 years. Mean age group for poisoning is 28 years. Young adults are affected more as they are more exposed to stressors like job, marital issues, financial problems etc., Sex-wise distribution of poisoning cases revealed that out of the total 353 cases, 160 cases i.e $(45.3 \%)$ were males and 193 cases i.e (54.7\%) were females and it is evident that the incidence of poisoning is more in case of females when compared to males (Table 1).
Poison wise distribution reveals among the 353 cases, the material of Maximum abuse was T.Alprazolam (10.8\%), followed by Rat Killer poison (9.6\%), and followed by Snake Strike (8.8\%), Organo Phosphorus Poisoning (8.5\%), and Multiple Tablet Overdose (8.2\%). Materials which are least used were mainly house hold items such as bleaching powder, match stick, nail polish and apart from it substances such as diesel, cracker powder, crude oil, datura, and allopathic medicines were also used (Table 3 ). In 15 cases, the material consumed was not known and some 7 cases reported with unknown Bite. This clearly indicates that from the old trend of pesticide poisoning, tablet overdose has occupied the place of it. This can be due to two reasons. One, as the hospital is a tertiary care centre with most of the cases who are admitting here belong to a middle to higher socio-economic status, their common source or affordable poison are the tablets. Among the tablets alprazolam tops the list. The second reason is the easy availability of the tablets and the strict laws on pesticide purchase. The second new entry to the list is the rat killer, which now comes in paste containing yellow phosphorus in it. These two are the new materials used for poisoning which was not found in any of the studies 
which we came through. In most of the studies like that of mani et al, which revealed that organophosphorous compounds are the most commonly consumed poison in both sexes during the study period. Similar study carried out by Bharath K Guntheti Udaypal Singh 5 stated that insecticide poisoning was the commonest poison $(77.86 \%)$ in which organophosphorous was the common compound (74.10\%) followed by organochlorines $(2.39 \%)$ and carbamates $(1.39 \%)$. Study conducted by Ramanath K.V. Naveen Kumar H.D 7 reported that pesticide poisoning in $57.5 \%$ cases is more common followed by bites (Snake bite/Bee sting) 13.6\%. Study conducted by, Dr. Gargi.J, Dr. Hakumat Rai, Dr. Ashok Chanana, Dr.Gurmanjit Rai et al 9 stated that Aluminium phosphide poisoning is commonest 38.23\% followed by Organophosphorous compounds 17.64\%. Study conducted by Tejas Prajapati, Kartik Prajapati, Rakesh Tandon, Saumil Merchant 11 revealed that the most common was pesticides $(33.9 \%)$, followed by household chemicals (26.8\%). Study conducted by, Subash Vijaya Kumar, Venkateswarlu.B, Sasikala.M, and Vijay Kumar.G 12 reported that pesticide poisoning $29.55 \%$ is the commonest followed by bites (snake, scorpion, unknown bite) $26.83 \%$. Study conducted by Vinay B shetty. Gurudatta S Pawar., Inamadar. P.I.,13 reported that the commonest type of poisoning was with organophosphorous compounds (73.14\%). Study conducted by Ansam F Sawalha., Waleed M Sweileh., Maysoon T Tufaha. and Dua Y Al-jabi. 15 reveals that animal envenomation (72.5) was the commonest type of poison. "Use it to Dye not to Die" A study conducted at Sri Venkateswara Institute of medical sciences (SVIMS University) Tirupati - Andhra Pradesh.14 indicates that hair dye poisoning is the new emerging suicidal poisoning more so in case of females with a male female ratio of $(1: 2.4)$. But in our study, we didn't have even a single case of hair dye poisoning.

Manner of poisoning reveals that majority of the cases, $78 \%$ consumed poison intentionally and are suicidal in nature, as no cases of homicidal poisoning are reported in the study group, rest of the $22 \%$ of cases, are of accidental in nature.

Till date, hanging is the most common method of committing suicide but poisoning is on a new trend. Apart from really committing suicide, poisoning nowadays is mainly used as a method to threaten people of committing suicide. Studies conducted by, Dr. Gargi.J, Dr. Hakumat Rai, Dr. Ashok Chanana, Dr.Gurmanjit Rai etal 11, Unnikrishnan B, Singh B, Rajeev A6, Vinay B shetty.
Gurudatta S Pawar., Inamadar. P.I 15, have also reported that suicidal poisoning is more common than homicidal poisoning. In the study conducted by, Ramanath K.V. Naveen Kumar H.D 10,

In our current study mortality wise analysis showed that Dead cases count 13 in number which accounts to $3.5 \%$ of all poisoning cases. Out of 13 cases, Paraquat and rat killer (Yellow Phosphorus) caused death of 3 persons each, followed by Organo - phosphorus compound, snake strike, unknown poisoning caused death of 2 persons each and oleander 1 person. Study conducted by Bharath K Guntheti Udaypal Singh 5 reported that overall mortality rate was $17.33 \%$. Overall mortality rate in the study conducted by Shoaib Zaheer.M, Aslam.M, Vibanshu Gupta, Vibhor Sharma and Shadab Ahmad Khan 15 was found to be $14.4 \%$. Overall mortality rate in the study conducted by Unnikrishnan B, Singh B, Rajeev A was 5.7\% 5 and the overall mortality rate in the study conducted by, Tejas Prajapati, Kartik Prajapati, Rakesh Tandon, Saumil Merchant 12 was reported to be $18.6 \%$.

\section{Conclusion}

Poisoning is more common among the adult age group, with a mean of 28 years.

Poisoning was more common among females when compared to males.

In the context of poisoning, the most common and an emerging trend change is from pesticides to tablets. T.Alprazolam leads the way with maximum incidence followed by Rat Killer poison, snake strike, Organo Phosphorus poisoning, and multiple tablet overdose .Household items like bleaching powder, match stick, nail polish and other products like diesel, cracker powder, crude oil, Datura, and allopathic tablets are also in increasing trend.

$78 \%$ of cases are suicidal whereas $22 \%$ were accidental in manner and $3.5 \%$ of death was reported from our study

Paraquat was the deadliest poison with both free radical action along with the corrosive action causing death of 3 out of 6 .

Rat killer (Yellow Phosphorus - paste form) and oleander are equally dangerous.

As attempts to commit suicide are on the rise, identifying the cause and treating the suicidal tendencies 
due to psychological issues is vital in prevention of further attempts. Hence, in our institution all cases of suicidal poisoning (those who survived) were referred to the department of psychiatry and psychiatric counseling was given to all the cases of suicidal poisoning.

Annexure 1:

Standardization Criteria.

Division of a Day.

\begin{tabular}{|l|l|}
\hline Morning & 6.00 A.M -12.00 P.M \\
\hline Afternoon & 12.00 P.M -6.00 P.M \\
\hline Evening & 6.00 P.M -12.00 A.M \\
\hline Night & 12.00 A.M -6.00 A.M \\
\hline
\end{tabular}

$\varnothing$ Conflict of Interest: Nil

$\varnothing$ Source of Funding: Self

$\varnothing \quad$ Ethical Clearance: The study was approved by the Ethics committee of the institute.

\section{References}

1. Krishnan V, Text Book of Forensic Medicine and Toxicology Principles \& Practice. 5th ed. New Delhi: Reed Elsevier India Pvt Ltd; 2011.

2. Pillay V V. Modern Medical Toxicology. 4th Ed. Delhi: Jaypee Brothers Medical Publishers Pvt Ltd; 2013.

3. Poisoning prevention and management [Internet]. 2012. Available from: https://www.who.int/ipcs/ poisons/en/.

4. Vinesh Shah B. Changing trends of poisoning in Surat city [Ph.D Thesis]. South Gujarat University; 2007.

5. Guntheti BK, Singh UP. The pattern of Poisoning in khammam. J Indian Acad Forensic Med. 2011; 33:296-300.
6. Unnikrishnan B, Singh B, Rajeev A. Trends of acute poisoning in south Karnataka. Kathmandu Univ Med J (KUMJ). 2005;3(2):149-54.

7. Sawalha B, Sweileh WM, Tufaha MT. and Al-jabi DY. Analysis of the pattern of acute poisoning in patients admitted to a government hospital in Palestine. Bari \& Clinical Pharmacological society. 2010;914-918.

8. Pokhrel D, Pant S, Pradhan A, Mansoor S. A ComparativeRetrospectiveStudyofPoisoningCases in Central, Zonal and District Hospitals. Kathmandu University Journal of Science, Engineering and Technology. 2008;4(1):40-48.

9. Shreemanta Kumar Dash, Manoj Kumar Mohanthy, Kiran Kumar Patnaik, Sachidananda Mohanthy, "Socio Demographic Profile of Poisoning Cases" JIAFM, 2005, 27 (3). ISSN 0971-0973, Page 133-138.

10. Ramanath KV, Naveen Kumar HD. Study the assessment of poisoning cases in rural Tertiary care teaching Hopsital. Asian J Pharm Clin Res. 2012;5(2).

11. Gargi J, Rai H, Chanana A, Rai G. Current trends of Poisoning - A Hospital profile. J Punjab Acad Forensic Med Toxicol. 2017;17(2): 38-42.

12. Prajapati T, Prajapati K, Tandon R, Merchant S. Acute chemical and pharmaceutical poisoning cases treated in civil Hospital, Ahmedabad. Asia Pac J Med Toxicol. 2013;2(2):63-67.

13. Kumar SV, Venkateswarlu B, Sasikala M, Kumar G V. A study on poisoning cases in a tertiary care hospital. J Nat Sc Biol Med. 2010;1:35-9

14. Shetty VB, Pawar GS, Inamadar PI. Profile of poisoning cases in district and medical college hospitals of north Karnataka. Indian J. Forensic Med. Toxicol. 2008;2(2):26-28.

15. Zaheer MS, Aslam M, Gupta V, Sharma V, Khan SA. Profile of Poisoning cases at a North Indian tertiary care hospital. Health and Population. 2009;32(4):176-183. 